\title{
The MLH1 -93 promoter variant influences gene expression
}

\author{
Manxue Mei ${ }^{\mathrm{a}}$, Dong Liu ${ }^{\mathrm{b}}$, Shuo Dong ${ }^{\mathrm{c}}$, Sigurdur Ingvarsson ${ }^{\mathrm{d}}$, Paul J. Goodfellow ${ }^{\mathrm{e}}$, Huiping Chen ${ }^{\mathrm{b}, *}$ \\ ${ }^{a}$ Department of Feed Science, Hubei Key Laboratory of Animal Nutrition and Feed Science, Wuhan Polytechnical University, Wuhan, Hubei, China \\ ${ }^{\mathrm{b}}$ Department of Medical Genetics, Tongji Medical College, Huazhong University of Science and Technology, Hangkong Lu 13, Wuhan, Hubei 430030, China \\ ' Department of Medicine, Baylor College of Medicine, Houston, TX, USA \\ ${ }^{\mathrm{d}}$ Institute for Experimental Pathology and Faculty of Medicine, University of Iceland at Keldur, Reykjavik, Iceland \\ e Department of Surgery, Washington University School of Medicine, St. Louis, MO, USA
}

\section{A R T I C L E IN F O}

\section{Article history:}

Accepted 9 December 2009

\section{Keywords:}

MLH1

-93 SNP

Promoter methylation

Gene expression

\begin{abstract}
A B S T R A C T
The -93 SNP of MLH1 gene is associated with MLH1 gene methylation in endometrial and colorectal cancers. We undertook luciferase reporter assay and electrophoretic mobility shift assay (EMSA) to test whether the -93 SNP affects the MLH1 gene expression. The luciferase activity for $-93 \mathrm{~A}$ plasmid is significantly lower than $-93 \mathrm{G}$ plasmid. In EMSA experiments, the $-93 \mathrm{~A}$ and $-93 \mathrm{G}$ probes have different binding affinity to nuclear proteins of JEG3 cells. Our data indicate that -93 SNP affects MLH1 gene expression by altering protein binding to the promoter of $M L H 1$ gene.
\end{abstract}

(C) 2009 Elsevier Ltd. All rights reserved.

\section{Introduction}

Loss of DNA mismatch repair leading to microsatellite instability (MSI) is seen in a high proportion of gastrointestinal and endometrial cancers. Epigenetic silencing of the MLH1 gene is the most common cause of defective DNA mismatch repair [1-7]. In a large series of endometrial carcinomas, $>20 \%$ have $M L H 1$ gene promoter methylation [1]. However, the molecular mechanism behind the methylation is not clear. We have previously shown that MLH1 gene methylation is associated with the -93 SNP of the MLH1 gene [8]. In this study, we undertook luciferase reporter assay and EMSA to further test whether -93 SNP of the MLH1 gene affects gene expression.

In the MLH1 gene promoter region, Arita et al. [9] identified a protein-binding site which contains -93 SNP, by in vivo footprinting analysis. It is conceivable that $-93 \mathrm{G}$ to A transition may change the protein binding at that site, and regulate MLH1 gene expression by altering its epigenetic status.

\section{Materials and methods}

\subsection{Cells and cell culture}

The human choriocarcinoma cell line JEG3 was obtained from American Type Culture Collection (Rockville, MD, USA) and cultured in RPMI-1640 medium (Hyclone, USA) supplemented

\footnotetext{
* Corresponding author. Tel.: +86 278369 2609; fax: +86 2783692608 .

E-mail address: huiping@mail.hust.edu.cn (H. Chen).
}

with $10 \%$ fetal bovine serum (Hyclone, USA). Cells were maintained in $5 \% \mathrm{CO}_{2}$ in air in a humidified atmosphere at $37{ }^{\circ} \mathrm{C}$. Exponentially growing cells were used for the following experiments.

\subsection{Construction of $-93 G$ and $-93 A$ reporter plasmids}

Arita et al. determined the minimal region, -301 to -76 relative to a translation start site, which is essential for transcription [9]. An insert, -301 to +101 of $M L H 1$ 5'-flanking region containing $-93 \mathrm{SNP}$, was amplified by the polymerase chain reaction (PCR). PCR was performed in $0.5 \mathrm{ml}$ tubes $(20 \mu \mathrm{l}$ volume, $0.3 \mathrm{U}$ of Pyrobest DNA polymerase (Takara Shuzo Co., Kyoto), $0.8 \mu \mathrm{l}$ of $4 \mu \mathrm{M}$ forward and reverse primers, $0.8 \mu \mathrm{l}$ of $2.5 \mathrm{mM}$ each dNTP, $20 \mathrm{ng}$ of genomic DNA and $1 \times$ Pyrobest Buffer II). Sense primers were designed to contain XhoI site (underlined): 5'-TAATCCGCTCGAGCCGAGCTCCTAAAAACGAACC-3'. The antisense primer contained HindIII site (underlined): 5'-GCATCCCAAGCTTCTTTGATAGCATTAGCTGGC-3'. PCR products were double digested with XhoI and HindIII. Gel purified digests were ligated in the XhoI and HindIII sites of pGL3-Basic (Promega Co., Madison, WI, USA) with T4 DNA ligase to give pGL3-MLH1-93G and pGL3-MLH1-93A. Plasmids were purified with a GFX Micro Plasmid Prep kit (Amersham Pharmacia Biotech, Inc., Piscataway, NJ, USA) according to a manufacturer's manual. DNA sequencing of constructs was performed using an RVprimer3 (sense, Promega) and a BigDye Terminator Cycle Sequencing kit (Applied Biosystems, Foster City, CA, USA) as recommended by the supplier. The reaction mixture was analysed on an automated DNA sequencer, ABI PRISM 3700 DNA Analyzer (Applied Biosystems). 


\subsection{Luciferase reporter gene analysis}

JEG3 cells were transfected with reporter plasmids and the luciferase activity was measured using Dual-Luciferase ${ }^{\circledR}$ Reporter (DLR) Assay kit (Promega) as instructed by the supplier. Firefly luciferase units were normalised with Renilla luciferase units, and the pGL3-Promoter (Promega) and the pGL3-Basic were used as a positive and negative control respectively. Each transfection was repeated 12 times.

\subsection{Electrophoretic mobility shift assay (EMSA)}

Nuclear extract of JEG3 cells was prepared using NE-PER Nuclear and Cytoplasmic Extraction kit (Pierce, Rockford, IL, USA) as described in the manual, and the protein content was determined by a Bradford method. Synthetic single strand oligonucleotide, -119 to -61 containing -93 SNP, was endlabelled with biotin using Biotin 3' End DNA Labeling kit (Pierce) as instructed by the supplier. The end-labelled forward and reverse single strand oligonucleotides were annealed by heating at $95{ }^{\circ} \mathrm{C}$ for $3 \mathrm{~min}$ in the presence of $200 \mathrm{mM} \mathrm{NaCl}$ and slowly cooling to room temperature. As a competitor, unlabelled probe ( -119 to -61$)$ or control EBNA DNA (5'-GTA CCC GGG GAT CCT ATC TGG GTA GCA TAT GCT ATC CTA ATG GAT CCT CTA GAG TCG ACC-3') from LightShift ${ }^{\circledR}$ Chemiluminescent EMSA kit (Pierce) was used. The binding reaction was performed for $20 \mathrm{~min}$ at room temperature in $20 \mu \mathrm{l}$ of binding buffer containing $20 \mathrm{fmol}$ of labelled probe, $1 \mu \mathrm{g}$ of poly dI-dC, and $6 \mu \mathrm{g}$ of nuclear extract. Separation of free biotin-labelled DNA from DNA-protein complexes was carried out on a $6.5 \%$ non-denaturing polyacrylamide gel. Electrophoresis was carried out in $0.5 \times$ TBE buffer at $100 \mathrm{~V}$ at room temperature. Electrophoretic transfer was performed in $0.5 \times$ TBE buffer at $340 \mathrm{~mA}$ for $1 \mathrm{~h}$ at room temperature. UV-light cross-linking was performed for $15 \mathrm{~min}$ with the membrane face down on a transilluminator equipped with $302 \mathrm{~nm}$ bulbs. Detection of the biotin-labelled DNA was undertaken using chemiluminescent Nucleic Acid Detection kit (Pierce) according to the manufacturer's instructions.

The intensity of the bands detected by EMSA was examined by using QUANTITY ONE 4.62 (Bio-Rad). Totally three experiments were done. Then the average of intensity was calculated.

In the antibody experiment, $1 \mu \mathrm{l}$ of AP-4 antibody $(2 \mu \mathrm{g} / \mu \mathrm{l}$, sc18593, Santa Cruz) was added and incubated for $20 \mathrm{~min}$, and then the biotin-labelled probe was added and incubated for another $20 \mathrm{~min}$ before loading into the gel.

\section{Statistical analysis}

The difference between luciferase activity of pGL3-MLH1-93G and pGL3-MLH1-93A, and band intensity of EMSA was analysed by unpaired Student's $t$-test (two tails).

\section{Results}

\subsection{Luciferase activity comparison of MLH1-93G and MLH1-93A plasmids}

In order to ascertain whether the -93 SNP of MLH1 gene affects gene expression, a DNA fragment, which covers -301 to +101 of MLH1 gene, was inserted into pGL3-Basic and transfected to human choriocarcinoma cell line, JEG3. The sequencing data showed that the cloned sequences and the junctons of inserts and vectors are correct. The luciferase activity of MLH1-93G plasmid was significantly higher than MLH1-93A plasmid $(p=0.002)$ (Fig. 1).

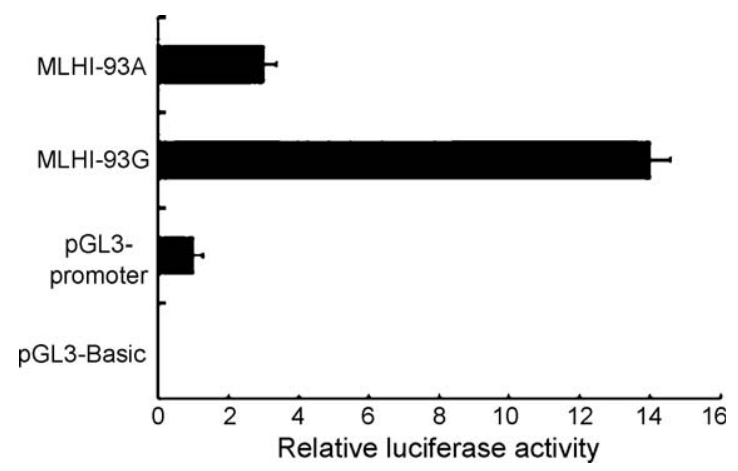

Fig. 1. Luciferase activity comparison of $-93 \mathrm{~A}$ and $-93 \mathrm{G}$ plasmids. The mean activity of the pGL3-promoter was set at 1 and the relative activity of each construct was calculated. Data shown are the mean $\pm \operatorname{SD}(n=12)$. $p$-Value was calculated between the activity of pGL3-MLH1-93G and pGL3-MLH1-93A: $p=0.002$.

\subsection{Binding proteins at the DNA fragment containing -93 SNP}

In order to understand whether the -93 SNP affects protein binding to the MLH1 gene promoter, the nuclear extracts of JEG3 were incubated with biotin-labelled oligonucleotide containing -93 SNP in the DNA binding buffer containing poly dI-dC. The EMSA results showed that some proteins bound to $-93 \mathrm{G}$ probe with higher intensity (arrows 1 and 2, Fig. 2; $p<0.0001$ and $p<0.0001$, Table 1 ), and some proteins bound to $-93 \mathrm{~A}$ probe with higher affinity (arrows 3-5, Fig. 2; $p=0.0001, p=0.0048$ and $p<0.0001$, Table 1 ). These proteins specifically interacted with $-93 \mathrm{G}$ and $-93 \mathrm{~A}$ probes, because specific competition could inhibit them; however, non-specific competition could not inhibit them (Fig. 2).

In a super gel shift assay with AP-4 antibody, no super-shifted bands were observed (data not shown).

\section{Discussion}

It is noteworthy that the $-93 \mathrm{~A}$ allele of $M L H 1$ gene was previously associated with risk for squamous cell lung cancers in Korean patients [10]. The lung cancers were not, however, evaluated for MLH1 methylation and epigenetic silencing. Recent studies in Chinese and American non-small-cell lung cancers have shown that methylation of the MLH1 promoter and/or epigenetic silencing of $M L H 1$ is a frequent event $[11,12]$. It is conceivable that the $-93 \mathrm{~A}$ allele is also associated with risk for MLH1 methylation in lung cancers and possibly in other malignancies. How variation in

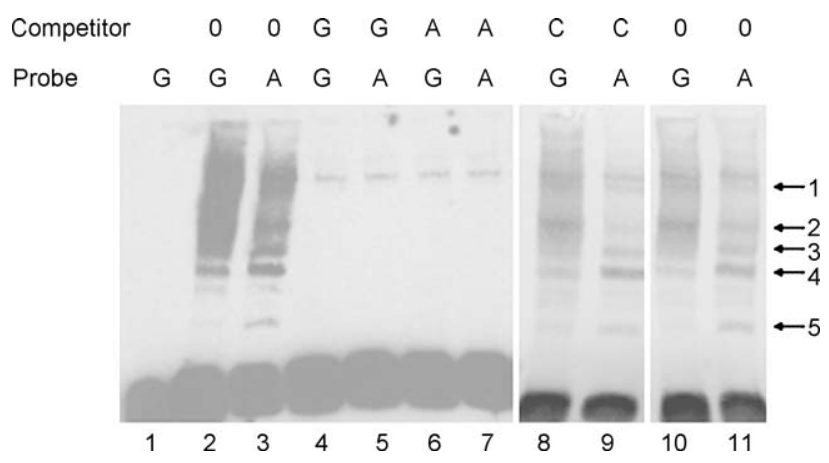

Fig. 2. Determination of the protein-binding to -93 SNP of MLH1 gene by EMSA. The complete reaction mixture contained nuclear extract of JEG3 and biotin-labelled -93 SNP containing oligonucleotide. G stands for probe containing -93G; A for probe with -93A. As a competitor, 200-fold excess amount of the unlabelled $\mathrm{G}$ or $\mathrm{A}$ or C (control EBNA DNA) was used. Lanes 2 and 3, no competitor added. Lanes 10 and 11 , repeats of lanes 2 and 3 (second experiment). Shifted bands are indicated by arrows $1,2,3,4$ and 5 . 
Table 1

The intensity comparison of bands indicated by arrows in Fig. 3.

\begin{tabular}{lllr}
\hline Band number & \multicolumn{2}{c}{ Average intensity } & $p$-Value \\
\cline { 2 - 3 } & Probe G & Probe A & \\
\hline 1 & 219.24 & 155.25 & $<0.0001$ \\
2 & 250.76 & 188.94 & $<0.0001$ \\
3 & 119.56 & 145.82 & 0.0048 \\
4 & 130.59 & 211.21 & 0.0001 \\
5 & 81.43 & 150.61 & $<0.0001$ \\
\hline
\end{tabular}

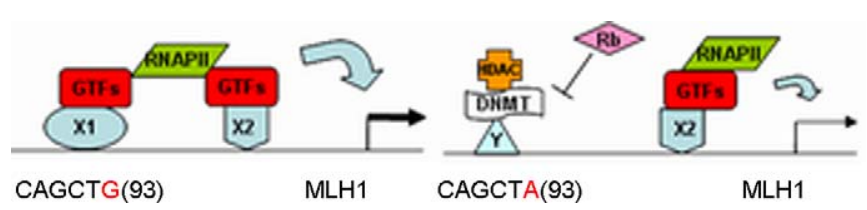

Fig. 3. The two possible models for -93 SNP regulating $M L H 1$ gene transcription (see main text for details).

the $5^{\prime}$ region of the $M L H 1$ gene influences risk for epigenetic silencing is yet to be determined. Recent studies have suggested that site-specific repressors of transcription may recruit DNA methyltransferases, leading to de novo gene methylation and epigenetic silencing $[13,14]$.

Based on footprinting experiments and reporter constructs, the associated variant ( $-93 \mathrm{SNP}$ ) is part of the $5^{\prime} M L H 1$ sequences that bind an unknown factor and are required for optimal expression [9]. Our data suggest that -93 SNP may alter protein binding to gene promoter to influence gene expression. The $-93 \mathrm{~A}$ plasmids showed significantly lower luciferase activity than -93G plasmids, possibly explained by the $G$ to A transition, which could allow a repressor to replace an active transcription factor. And then the cloned MLH1 promoter of the $-93 \mathrm{~A}$ plasmids could be methylated. The EMSA data support the above speculation, because some proteins bind to the $-93 \mathrm{G}$ probe with higher affinity and some to the $-93 \mathrm{~A}$ probe with higher affinity. With respect to $-93 \mathrm{G}$, it could possibly interact with a transcription factor (X1), which might recruit general transcription factors (GTFs) and RNA polymerase II $[15,16]$, leading to $M L H 1$ gene transcription. A previous study reported that there are 6 protein-binding sites within the MLH1 gene promoter [9]. Therefore, the MLH1 gene promoter may contain an additional transcription factor (X2) binding site, which could further enhance gene transcription (Fig. 3, left). With respect to $-93 \mathrm{~A}$, it might interact with a repressor $(\mathrm{Y})$, which could recruit co-repressors including DNA methyltransferase (DNMT), histone deacetylase (HDAC) etc. DNMT activity could be inhibited by the retinoblastoma $(\mathrm{Rb})$ protein [17], resulting in negative methylation status of the MLH1 promoter. However, the X2 could still drive low-level transcription of the MLH1 gene (Fig. 3, right). The proposed model provides a good explanation of what we have seen in luciferase reporter assays. If DNMT activity is increased, or $\mathrm{Rb}$ function is lost, the DNMT could make the MLH1 gene promoter methylated, and gene transcription would be turned off.

Using software to search for transcription factors, we found that the $-93 \mathrm{G}$ of the MLH1 gene could possibly bind to a transcription factor, Activating Enhancer Binding Protein 4 (AP-4). However, the super gel shift assay with AP-4 antibody did not show any supershifted bands, indicating that transcription factor AP-4 does not interact with $-93 \mathrm{G}$ of the MLH1 gene. Further studies to isolate those proteins binding to $-93 \mathrm{G}$ and A probes, and analyse their functions associated with gene methylation and transcription, should help clarify that the -93 SNP participates in regulation of methylation and transcription of the MLH1 gene.

\section{Conflict of interest}

None declared.

\section{Acknowledgements}

We thank Anna Yates for her critically reviewing the manuscript. This project was supported by the Huazhong University of Science and Technology (24510101 and 25510026).

\section{References}

[1] Goodfellow PJ, Buttin BM, Herzog TJ, Rader JS, Gibb RK, Swisher E, et al. Prevalence of defective DNA mismatch repair and MSH6 mutation in an unselected series of endometrial cancers. PNAS 2003;100:5908-13.

[2] Kane MF, Loda M, Gaida GM, Lipman J, Mishra R, Goldman H, et al. Methylation of the hMLH1 promoter correlates with lack of expression of hMLH1 in sporadic colon tumors and mismatch repair-defective human tumor cell lines. Cancer Res 1997;57:808-11.

[3] Esteller M, Levine R, Baylin SB, Ellenson LH, Herman JG. MLH1 promoter hypermethylation is associated with the microsatellite instability phenotype in sporadic endometrial carcinomas. Oncogene 1998;17:2413-7.

[4] Simpkins SB, Bocker T, Swisher EM, Mutch DG, Gersell DJ, Kovatich AJ, et al. MLH1 promoter methylation and gene silencing is the primary cause of microsatellite instability in sporadic endometrial cancers. Hum Mol Genet 1999;8:661-6.

[5] Cunningham JM, Kim CY, Christensen ER, Tester DJ, Parc Y, Burgart LJ, et al. The frequency of hereditary defective mismatch repair in a prospective series of unselected colorectal carcinomas. Am J Hum Genet 2001;69:780-90.

[6] Kakar S, Burgart LJ, Thibodeau SN, Rabe KG, Petersen GM, Goldberg RM, et al Frequency of loss of hMLH1 expression in colorectal carcinoma increases with advancing age. Cancer 2003;97:1421-7.

[7] Hampel H, Frankel WL, Martin E, Arnold M, Khanduja K, Kuebler P, et al Screening for the Lynch syndrome (hereditary nonpolyposis colorectal cancer). N Engl J Med 2005;352:1851-60.

[8] Chen H, Taylor NP, Sotamaa KM, Mutch DG, Powell MA, Schmidt AP, et al. Evidence for heritable predisposition to epigenetic silencing of MLH1. Int J Cancer 2007;120:1684-8.

[9] Arita M, Zhong X, Min Z, Hemmi H, Shimatake H. Multiple sites required for expression in 5'-flanking region of the hMLH1 gene. Gene 2003;306:57-65.

[10] Park SH, Lee GY, Jeon HS, Lee SJ, Kim KM, Jang SS, et al. -93G $\rightarrow$ A polymorphism of hMLH1 and risk of primary lung cancer. Int J Cancer 2004;112:678-82.

[11] Wang YC, Lu YP, Tseng RC, Lin RK, Chang JW, Chen JT, et al. Inactivation of hMLH1 and hMSH2 by promoter methylation in primary non-small cell lung tumors and matched sputum samples. J Clin Invest 2003;111:887-95.

[12] Safar AM, Spencer 3rd H, Su X, Coffey M, Cooney CA, Ratnasinghe LD, et al. Methylation profiling of archived non-small cell lung cancer: a promising prognostic system. Clin Cancer Res 2005;11:4400-5.

[13] Brenner C, Deplus R, Didelot C, Loriot A, Vire E, De Smet C, et al. Myc represses transcription through recruitment of DNA methyltransferase corepressor. EMBO J 2005;24:336-46.

[14] Brenner C, Fuks F. DNA methyltransferases: facts, clues, mysteries. Curr Top Microbiol Immunol 2006;301:45-66 [review].

[15] Maldonado E, Reinberg D. News on initiation and elongation of transcription by RNA polymerase II. Curr Opin Cell Biol 1995;7:352-61.

[16] Zawel L, Reinberg D. Initiation of transcription by RNA polymerase II: a multistep process. Prog Nucleic Acid Res Mol Biol 1993;44:67-108.

[17] Pradhan S, Kim GD. The retinoblastoma gene product interacts with maintenance human DNA (cytosine-5) methyltransferase and modulates its activity. EMBO 2002; 15, 21(4):779-88. 